\title{
Management of Acute Renal Failure in Septicemic Neonates at a Tertiary Care Hospital
}

\author{
Sajan. T. Nair', Varun P G ${ }^{2}$ \\ ${ }^{1}$ Assistant Professor, Department of Pediatrics, Mount Zion Medical College, Chayalode, Adoor, Kerala, ${ }^{2}$ Senior Registrar, Department of Pediatrics, Mount Zion Medical \\ College, Chayalode, Adoor, Kerala.
}

\section{Abstract}

Background: Neonatal septicemia or Sepsis neonatorum refers to systemic bacterial infection of infants during the first month of life. Infections are significant cause of mortality and long-term morbidity in neonates. The problem is that neonatal sepsis is a disease that may start with minimal or nonspecific symptoms and has a relatively low incidence, yet a high risk of mortality. Because the treatment is benign, relative to the disease and babies who develop sepsis often die rapidly, clinical practice has evolved such that many more babies are evaluated and treated for sepsis than have the condition, on the basis of subtle signs or risk factors, which resulted in over treatment. Subjects and Methods: This study was carried out in the neonatal intensive care units of the Pediatric Department of Medical College. The study includes the clinical profile of 100 cases of normal full-term neonates with septicemia admitted to the above centre during the period of study. Results: Most of the cases of acute renal failure required only conservative management $(48.2 \%)$ whereas $11.1 \%$ of cases required peritoneal dialysis.Most of the cases of intrinsic renal failure $(66.7 \%)$ required other modalities than conservative line in management, whereas most of the prerenal failure cases $(60.0 \%)$ required only conservative management. All instances of peritoneal dialysis were in intrinsic renal failure group. Conclusion: Blood culture was the diagnostic criteria used for septicemia and the commonest organisms isolated were E. Coll, Klebsiella, Coagulase positive staphylococci and Group-B streptococci.

Keywords: Management, Acute Renal failure, Septicemic neonates.

Corresponding Author: Dr. Varun P G, Senior Registrar, Department of Pediatrics, Mount Zion Medical College, Chayalode, Adoor, Kerala.

Received: December 2019

Accepted: December 2019

\section{Introduction}

Urine produced by the metanephric kidneys of 12-16 week old fetus contributes to the formation of amniotic fluid. Although renal function is not necessary for longterm regulation of fetal water and electrolyte homeostasis, a process assumed by placenta, it is important in normal growth, lung development and protection from acute changes in fetal vascular volume. The rateof urine production in normal fetuses is about $10 \mathrm{ml} / \mathrm{hr}$ at 30 weeks, increasing to $28 \mathrm{ml} / \mathrm{hr}$ at 40 weeks.

The fetus is unique in that excretory function is accomplished by continuous highly efficient hemodialysis by the placenta, which receives approximately $50 \%$ of the infant's cardiac output. Two kidneys of the adult which comprise $0.5 \%$ of the total body mass, receive approximately $20 \%$ of total cardiac output. In contrast the fetal kidneys receive only about $5 \%$ of the cardiacoutput.Renal blood flow increase progressively to $6 \%$ of cardiac output by the end of the first week, reaching $15 \%$ to $18 \%$ by the end month of life. There is also a redistribution of renal blood flow from renal cortex to outer cortex with maturation from fetus to adult type so that $93 \%$ of renal blood flow goes to an area which constitutes about $75 \%$ of renal mass at maturity. ${ }^{[1]}$

The rate of renal blood flow is determined by the cardiac output and the ratio of renal to systemic vascular resistance. Developmental changes in both determinants contribute to the postnatal increase in renal blood flow. Although it has been proposed that imposition of functional demand at birth causes a dramatic increase in renal blood flow, experimental evidence suggests that clamping of the umbilical cord doesnot in itself result in a sudden increase in renal blood flow. Primary factor responsible for the maturational increase in renal blood flow and change in intra renal distribution is a decrease in renal vascular resistance, the rise in cardiac output and mean arterial blood pressure accounting only partially. A major contribution to the evolution of the kidney from a high resistance, low-flow organ with most of the blood supplying the inner cortex, into a low resistance, high - flow organ, with most of the blood supplying the outer cortex is provided by anatomic changes in the renal vasculature. Several vasoactive substances suggested to have a role in the regulation of renal blood flow include, the renin - angiotensin system, the kallikrein-kinin system, prostaglandins, vasopressin and atrial natriuretic peptides. The renal nerves and adrenergic nervous system 


\section{Nair d Varun; Management of Acute Renal Failure in Septicemic Neanates at a Jertiary Care Haspital}

(catecholamines) also may play important roles in regulating renal vascular resistance in the neonate. ${ }^{[2,3]}$

Renin-Angiotensin system is very active in the fetus and newborn and plasma renin activity is inversely related to gestational age. Even then the plasma renin activity in newborn is 20 fold greater than in the adult. After a short increase postnatally for few days, it decreases gradually. High levels of plasma renin activity are associated with parallel levels of angiotensin-II and aldosterone. Although this renin- angiotensin system doesnot play a major role in the control of basal blood flow in the fetus and newborn normally, under conditions of stress like an acute reduction in fetal blood volume or fetal hypoxia results in significant increases in renin and angiotensin-II levels. ${ }^{[4]}$

Neonatal septicemia or Sepsis neonatorum refers to systemic bacterial infection of infants during the first month of life. Infections are significant cause of mortality and long-term morbidity in neonates.

The problem is that neonatal sepsis is a disease that may start with minimal or nonspecific symptoms and has a relatively low incidence, yet a high risk of mortality. Because the treatment is benign, relative to the disease and babies who develop sepsis often die rapidly, clinical practice has evolved such that many more babies are evaluated and treated for sepsis than have the condition, on the basis of subtle signs or risk factors, which resulted in overtreatment. The goals of the clinician are therefore to (i) develop a systematic approach to the diagnosis of neonatal sepsis based on the relative importance of the known symptoms and risk factors, (ii) miss no cases- this will required some overtreatment of newborns in the identified high-risk group, (iii) minimize duration of therapy for those high-risk infants who prove to be uninfected and (iv) provide a safe observation protocol for the low risk neonate. ${ }^{[5]}$

Incidence of neonatal sepsis ranges from 1 to 10 cases per 1000 live births with considerable variability over time, health and development status and geographic location of the place. As many as $2 \%$ of fetuses are infected utero and inflammatory lesions are found in about $25 \%$ of newborn autopsies. Figures reported from neonatal intensive care units are considerably higher and range from 5\% to $30 \%$. Approximately one third of septic newborns develop meningitis.

Neonatal septicemia can be divided into (i) Early onset septicemia - the onset before 72 hours of life and (ii) Late onset septicemia - the onset after 72 hours of life. Early onset septicemia is usually the result of exposure to microorganisms of maternal origin acquired from the mother transplacentally by hematogenous spread or by vertical transmission in utero, just prior to delivery or during the process of delivery. After birth the newborn infant may be exposed to infectious agents in the nursery or in the community. The commonest organisms responsible for early onset septicemia in India, include Gram negative organisms like E. Coli, Klebsiella and Enterobacter species, where as in the West, early onset infections are mostly caused by Group. B. Streptococci and E. Coli. ${ }^{[6]}$

Late onset septicemia can have an aetiologic agent transmitted from a variety of sources such as mother, family contacts, hospital personnel, environmental or contaminated hospital equipments. Most common organisms causing late onset septicemia are Gram negative bacilli like E. Coli, Enterobacteria, Pseudomonas aeruginosa, Alkaligenesefecalis, Salmonella typhimurium, Proteus, Citrobacter and Serratia while the rest are contributed by Gram positive organisms including Staphylococcus aureus and albus.

The timing of exposure in utero, inoculum size, immune status and the aetiological agent influence the expression of disease as which newborn will develop sepsis, meningitis or other serious invasive infections.

Risk of bacterial infection in the neonate may be (i) Prenatal risks - including maternal fever or afebrile infection, chorioamnionitis, preterm labour, premature rupture of membranes, prolonged or difficult labour, instrumentation or fetal tachycardia. (ii) Neonatal risks - including low birth weight, male sex, twins, certain congenital anomalies, birth asphyxia, difficult resuscitation, skin Wounds or low Apgar scores and (iii) Nosocomial risks -including length of hospital stay, invasive procedures, crowding in nursery, patient-nurse ratio, lack of handwashing, protracted antibiotic therapy or surgery. Newborns in India face other risks like - a good percentage of deliveries are conducted at home by untrained Dais who lack knowledge of asepsis, practice of prelacteal and top feeding, poverty, ignorance and inadequacy of health services. ${ }^{[4]}$

Bacterial colonization in the rectum, umbilicus, nasopharynx, ropharynx, ears, eyes, genitals and skin of the neonate occur in utero or from birth passage or from outside. Feeding initiates colonization of the gut. Heavy colonization with one group of microorganisms may predispose to local systemic infection.

The newborn infant may be less capable of responding to infection owing to one or more immunologic deficiencies involving the reticulo-endothelial system, complement, polymorphonuclear leucocytes, cytokines, antibody or cell mediated immunity. Due to deficiency of complement at birth, opsonic activity is markedly deficient. This coupled with IgM deficiency is responsible for greater susceptibility and vulnerability of newborns to infections, especially by Gram negative bacteria. Production of other mediators like interferon and fibronectin is also poor in newborns. ${ }^{[6]}$

\section{Subjects and Methods}

This study was carried out in the neonatal intensive care units of the Pediatric Department of Medical College.

The study includes the clinical profile of 100 cases of normal full-term neonates with septicemia admitted to the above centre during the period of study.

All normal, full term, appropriate for gestational age neonates, delivered normally or by Caesarean section, who were without antenatal, perinatal or immediate postnatal complications and without congenital anomalies, admitted after the first day of life to the N1CU, during the above mentioned period, with a clinical suspicion of septicemia were evaluated.

A detailed antenatal history was elicited to rule out familial 
Nair d Varun; Management of Acute Renal Failure in Septicemic Neanates at a Jertiary Care Haspital

renal malformations, complications like oligohydramnios, hemorrhage, infections, hypertension and antenatal ultrasonographic abnormalities. Natal history was taken to find out the type of delivery, indications of intervention, drugs used and other complications. Postnatal history comprising of perinatal asphyxia and other complications, time the neonate first voided urine, initiation of breast feeding or prelacteal feeds and details of examination at birth wherever possible were noted.

The presenting complaints with special reference to the aetiology of septicemia, possible factors to the development of acute renal failure, clinical features of presentation and complications if any were recorded. A detailed clincal examination was also carried out.

A sample of blood was taken for Blood urea (Diacetylmonoxime method), Serum creatinine (Modified Jaffe's method), Serum electrolytes (Auto analyser/Flame photometry), $\mathrm{Hb} \%$ (Sahli's method), Serum bilirubin (colorimetric), Peripheral smear, Total count, Differential count, and Blood culture. 24 hrs urine output was measured using condom catheters or empty disposable syringe sachets in males and perineal urine collection bags in females. Urine samples were sent for Albumin (sulphosalicylic acid method), Microscopy, Urine creatinine (modified Jaffe 's method), Urine sodium (Flame photometry/ Autoanalyser) and Urine culture wherever possible.

\section{Results}

\begin{tabular}{|l|l|l|l|}
\hline Table 1: Comparison of CSF for Meningitis \\
\hline $\begin{array}{l}\text { CSF for } \\
\text { meningitis }\end{array}$ & $\begin{array}{l}\text { Intrinsic Renal } \\
\text { Failure }\end{array}$ & $\begin{array}{l}\text { Prerenal } \\
\text { Failure }\end{array}$ & Total \\
\hline Present & 04 & 07 & 11 \\
\hline Absent & 08 & 08 & 16 \\
\hline
\end{tabular}

In this study high incidence of lower respiratory tract infection was seen in septicemia with acute renal failure $(40.7 \%)$. The incidence was more in prerenal failure (46.7\%) compared to intrinsic renal failure $(33.3 \%)$.

Nephrosonogram was done in all cases of intrinsic renal failure except in expired cases. Abnormal sonographic findings were noted in $55.6 \%$ of cases and $44.4 \%$ of sonograms were normal. In the abnormal sonograms, increased echotexture of kidneys was a consistent finding whereas increase in size of kidneys or loss of corticomedullary definition were noted in some cases.

In prerenal failure all nephrosonograms done were showing normal findings.

Most of the cases of acute renal failure required only conservative management (48.2\%) whereas $11.1 \%$ of cases required peritoneal dialysis.

Most of the cases of intrinsic renal failure (66.7\%) required other modalities than conservative line in management, whereas most of the prerenal failure cases $(60.0 \%)$ required only conservative management.

All instances of peritoneal dialysis were in intrinsic renal failure group.

Table 2: Mode of Treatment

\begin{tabular}{|l|l|l|l|l|}
\hline Group & $\begin{array}{l}\text { Mode Of } \\
\text { Treatment }\end{array}$ & $\begin{array}{l}\text { Intrinsic } \\
\text { Renal } \\
\text { Failure }\end{array}$ & $\begin{array}{l}\text { Prerenal } \\
\text { Failure }\end{array}$ & Total \\
\hline I & $\begin{array}{l}\text { Conservative } \\
\text { management alone }\end{array}$ & $\begin{array}{l}04 \\
(33.3 \%)\end{array}$ & $\begin{array}{l}09 \\
(60.0 \%)\end{array}$ & $\begin{array}{l}13 \\
(48.2 \%)\end{array}$ \\
\hline II & $\begin{array}{l}\text { Conservative } \\
\text { manage- }\end{array}$ & $\begin{array}{l}05 \\
(41.7 \%)\end{array}$ & $\begin{array}{l}06 \\
(40.0 \%)\end{array}$ & $\begin{array}{l}11 \\
(40.7 \%)\end{array}$ \\
& $\begin{array}{l}\text { ment with } \\
\text { transfusion }\end{array}$ & & & \\
\hline III & Peritoneal dialysis & 03 & 00 & 03 \\
& & $(25.0 \%)$ & $(00.0 \%)$ & $(11.1 \%)$ \\
\hline
\end{tabular}

Table 3: Mean duration of hospital stay

\begin{tabular}{|l|l|}
\hline Group & Mean duration \\
\hline Intrinsic renal failure & 13.6 days \\
\hline Prerenal failure & 9.0 days \\
\hline
\end{tabular}

In patients who recovered, mean duration of hospital stay was more in intrinsic renal failure group than in prerenal failure group.

Table 4: Outcome of Septicemia

\begin{tabular}{|l|l|l|l|}
\hline Outcome & Intrinsic Renal Failure & Prerenal Failure & Total \\
\hline Improved & 09 & 13 & 22 \\
\hline Expired & 03 & 02 & 05 \\
\hline
\end{tabular}

$81.5 \%$ of patients in this study improved, of which survival was more in prerenal failure group $(86.7 \%)$ compared to intrinsic renal failure group $(75.0 \%)$.

Mortality in intrinsic renal failure group (25.0\%) was about twice that in prerenal failure group (13.3\%).

Table 5: Diagnosis

\begin{tabular}{|l|l|l|l|}
\hline \multirow{2}{*}{ Diagnosis } & & \multicolumn{2}{|l|}{ Total Number Of } \\
\cline { 2 - 4 } & Expired & Studied & Percentage \\
\hline $\begin{array}{l}\text { Intrinsic renal failure with } \\
\text { septicemia }\end{array}$ & 03 & 12 & $25.0 \%$ \\
\hline $\begin{array}{l}\text { Prerenal failure with } \\
\text { septicemia }\end{array}$ & 02 & 15 & $13.3 \%$ \\
\hline Septicemia without renal failure & 09 & 73 & $12.3 \%$ \\
\hline Total & 14 & 100 & $14.0 \%$ \\
\hline
\end{tabular}

Mortality in septicemia without acute renal failure in this study was $12.3 \%$. When prerenal failure was associated, mortality increased to $13.3 \%$. But when septicemia was associated with intrinsic renal failure, mortality was almost twice $(25.0 \%)$.

Table 6: Oliguria versus Outcome
\begin{tabular}{|l|c|c|c|c|c|c|}
\hline Symptom & $\begin{array}{c}\text { Int. } \\
\text { Renal } \\
\text { Failure }\end{array}$ & Expired & $\begin{array}{c}\text { Pre- } \\
\text { Renal } \\
\text { Failure }\end{array}$ & Expired & Total & Expired \\
\hline Oliguria & 07 & 03 & 12 & 02 & 19 & 05 \\
& $(58.3 \%)$ & $(42.9 \%)$ & $(80.0 \%)$ & $(16.7 \%)$ & $(70.4 \%)$ & $(26.3 \%)$ \\
\hline Non- & 05 & 00 & 03 & 00 & 08 & 00 \\
Oliguria & $(41.7 \%)$ & $(00.0 \%)$ & $(20.0 \%)$ & $(00.0 \%)$ & $(29.6 \%)$ & $(00.0 \%)$ \\
\hline
\end{tabular}

Oliguria was present in majority $(70.4 \%)$ of acute renal failure patients with a high mortality $(26.3 \%)$. All expired 


\section{Nair \& Varun; Management of Acute Renal Failure in Septicemic Neanates at a Jertiary Care Haspital}

cases with acute renal failure had oluguria. Oliguria when present, mortality in intrinsic renal failure was more $(42.9 \%)$ compared to pre-renal failure (16.7\%).

\section{Discussion}

Blood culture positivity, which was the diagnostic criteria used for septicemia showed that in early onset septicemia, the common organisms isolated were E. colt, klebsiella, Group-B. streptococci and Acinetobacter, whereas late onset septicemia was produced by Coagulase positive staphylococci, E.coli and klebsiella mainly. There was no relation between aetiological organism and the type of renal failure precipitated. These findings were comparable to Somu .N, et al , Siegel and McCrackenand data in literature. ${ }^{[7]}$

Normocytic normochromic anemia was the commonest peripheral smear finding in intrinsic renal failure (41.7\%) and normal blood picture was seen more in prenenal failure (53.3\%). These were also comparable to other studies and data in literature. Leucopenia, toxic granulation and band forms were seen commonly in all cases. These are of diagnostic importance in septicemia of neonates.

Azotemia is a characteristic feature of acute renal failure. High values are more common in intrinsic renal failure compared to prerenal failure. Blood urea levels decrease gradually in intrinsic renal failure recovering with treatment whereas they decrease rapidly with adequate hydration and treatment of the cause in most of the prerenal failure cases. ${ }^{8}$

In the present study, blood urea levels were more than 40 $\mathrm{mg} \%$ in all cases on admission with higher values in intrinsic compared to prerenalfailure. High values persisted or increased in intrinsic renal failure for few days and decreased gradually in recovered cases. In prerenal cases azotemia came down rapidly and most of the values were within normal limits by the 3 rd day. These were comparable to the above data.

Mean peak blood urea levels in intrinsic renal failure and prerenalfailure were $164.2 \pm 100.6 \mathrm{mg} \%$ and $82.0 \pm 16.1$ $\mathrm{mg} \%$ respectively in the present study. Different values were seen in various studies in different clinical settings.

Serum creatinine is a more dependable diagnostic indicator of renal failure than blood urea. Serum creatinine values are higher in intrinsic renal failure than in prerenal failure. Serum creatinine levels decrease gradually in intrinsic renal failure recovering with treatment where as they fall rapidly with adequate hydration and treatment of the cause in most of the prerenal failure cases.

In the present study serum creatinine levels were more than $1.0 \mathrm{mg} \%$ in all cases on admission, with higher values in intrinsic compared to prerenalfailure. High values persisted or increased in intrinsic renal failure for few days and decreased gradually in recoverd cases. In prerenal failure the values decreased rapidly and most of the values were within normal by the 3rd day. These findings were comparable to the above data. ${ }^{[9]}$
Mean peak serum creatinine levels in intrinsic renal failure and prerenal failure were $3.9 \pm 2.5 \mathrm{mg} \%$ and $1.710 .5 \mathrm{mg} \%$ respectively, in the present study. Different values were seen in various studies in different clinical settings, like 5.2 \pm 1.7 by Pereira.$S$, et al, $5.0 \pm 1.9$ by Chevalier .RL, et al 3.3 by Anand .SK, et al and 1.2 to 2.2 by Jayashree, et al .High serum levels of creatinine were associated with increased mortality in the present study. ${ }^{[10,11]}$

In the present study mortality in septicemic newborns with intrinsic renal failure was $25.0 \%$ which was almost twice that of prerenal failure with septicemia $(13.3 \%)$ and septicemia with out renal failure $(12.3 \%)$. These figures show that development of acute renal failure definitely increase the mortality in septicemia.

These figures were comparable to Griffin, et al where the mortality in septicemic neonates with acute renal failure was $25.0 \%$. The mortality in the present study was in contrast to Jayashree, et al where a mortality of $50.0 \%$ was seen in septicemic neonates with acute renal failure. This difference may be due to the use of other modalities of treatment in the present study where asJayashree, et al used conservative line of management alone. ${ }^{[12]}$

Mortality in other studies, where all the newborns with acute renal failure were studied, were higher than the present study. This ranged from $25.0 \%$ to $75.0 \%$. This may be due to other factors like prematurity, low birth weight, perinatal complications, congenital renal abnormalities and other acquired causes, each in turn increase the mortality.

\section{Conclusion}

Common clinical symptoms were weak cry, refusal of feeds, oliguria, hurried respiration, vomiting, convulsions, cyanosis, hypothermia and fever. Common physical signs were lethargy, weak reflexes, abdominal distension, dehydration, respiratory distress, anemia, hepatomegaly, jaundice, acidosis, sclerema and apnoea.

\section{References}

1. Shaffer. SE, Norman .ME : Renal function and renal failure in the newborn. ClinPerinatol, 1989; 16 (1): 199-217.

2. Bergstein .JM : Acute renal failure In ; Behrman .RE, Kliegman .RM (eds) Nelson Text Book of Pediatrics, 14th Edn, W.B. Saunders Co., Philadelphia, 1992; 18(35): 1352-1355.

3. Conger .JD, Schrier .RW : Acute renal failure In : Strauss .J (ed) Pediatric Nephrology, Vol 4, Garland STPM Press, New York, 1974: $1-110$.

4. Siegel .NJ, Vanwhy .SK, Boydstun .11, Devarajan .P, Gaudio .KM: Acute renal failure In : Holliday .MA, Barratt .TM, Avner .ED (eds) Pediatric Nephrology, 3rd Edn, Williams and Wilkins, Baltimore, 1994; 58: 1176-1203.

5. Mehta .KP : Neonatal renal failure. IndPediatr 1991; 28: 7-9.

6. Chevalier .RL : Renal disease in neonates In : Postlethwaite. RJ (ed) Clinical Pediatric nephrology, 2nd Edn, Butterworth-Heinemann Ltd, Oxford, 1994; $31: 373-388$.

7. 7 Arant .BS Jr : Developmental patterns and renal functional maturation compared in the human neonate. J. Pediatr 1978; 92(5) : 705-712.

8. Nair .PAK, Mohan . VM, Karan .S : Study of neonatal kidney 
Nair d Varun; Management of Acute Renal Failure in Septicemic Neanates at a Jertiary Care Faspital

functions in preterm and term babies. Ind J Pediatr 1987; 54: 59-63.

9. 9 Gotoff .SP : Infections of the newborn In : Behrman .RE, Kliegman RM (eds), Nelson Text Book of Pediatrics, 14th Edn, W.B. Saunders Co., Philadelphia, 1992; 9(60): 495-524.

10. Siegel .JD, McCracken .GH Jr : Sepsis neonatorum. NEJM, 1981; 304(11): 642-647.

11. Freij .BJ, McCracken .GH Jr : Acute infections In: Avery. GB, Fletcher .MA, Mac Donald .MG (eds) Neonatology - Pathophysiology and management of newborn, 4th Edn, J.B. Lippincott Co.,
Philadelphia, 1994; 48: 1082-1116.

12. Singh .M : Perinatal infections In : Care of the newborn, 4th Edn, Sagar Publications, Delhi, 1991; 12: 154-176.

Copyright: (C) the author(s), 2019. It is an open-access article distributed under the terms of the Creative Commons Attribution License (CC BY 4.0), which permits authors to retain ownership of the copyright for their content, and allow anyone to download, reuse, reprint, modify, distribute and/or copy the content as long as the original authors and source are cited.

How to cite this article: Nair ST, Varun PG. Management of Acute Renal Failure in Septicemic Neonates at a Tertiary Care Hospital. Asian J. Clin.Pediatr.Neonatol.2019;7(4):22-26.

DOI: dx.doi.org/10.21276/ajcpn.2019.7.4.5

Source of Support: Nil, Conflict of Interest: None declared. 